\title{
PERCUTANEOUS WALLSTENT INSERTION IN MALIGNANT BILIARY OBSTRUCTION AFTER A FAILED THERAPEUTIC ERCP
}

\author{
HJ Tan, SpR in Gastroenterology; M Akhtar, SpR in Gastronenterology; \\ BA Teague, Clinical Audit Manager; HM Pratt, Clinical Audit Assistant; \\ CS Ball, Consultant Surgeon; JJ Keating, Consultant Gastroenterologist, \\ Furness General Hospital
}

\section{INTRODUCTION}

The self-expanding biliary metal stent has been shown to have a longer patency compared to the polyethylene stent and is therefore a good alternative in patients with malignant biliary stricture. This is especially useful in patients unsuitable for open surgery. Several randomised trials ${ }^{(1,2,3)}$ showed no significant difference in longterm survival between patients treated with surgical bypass and stenting. Endoscopic stenting results in lower procedural-related mortality, shorter hospital stay and a lower major complication rate, whereas surgical bypass is associated with fewer late complications such as stent clogging, which necessitate re-admission. This retrospective study evaluates our experience of percutaneous Wallstent insertion after a failed endoscopic (ERCP) stent insertion.

\section{PATIENTS AND METHODS}

Between February 1996 and January 1999, 283 ERCP studies were performed. Nineteen patients $(6.7 \%)$ with advanced malignant obstructive biliary disease underwent percutaneous metal stent insertion following a failed endoscopic approach due to their advanced disease. Seventeen $(89.5 \%)$ were successful. Eight patients had pancreatic tumour, five had liver metastases from either lung or colorectal tumour and four had cholangiocarcinoma. Curative operation was considered unsuitable in all the cases because of comorbidity, operative risk factors and the advanced disease stage. The level of activity of daily living, the decrease in bilirubin, symptoms improvement (reduced pruritus and improved appetite), and the hospital re-admission rate for stent-related complications were assessed. The complication and mortality rates were then compared to the published data.

The Wallstent prostheses were placed percutaneously by a radiologist. Thirteen patients were given intravenous antibiotic and all were given lignocaine, midazolam and pethidine for the procedure. The Wallstents used were either $10 \mathrm{~mm} \times 9 \mathrm{~cm}$ or $10 \mathrm{~mm} \times 7 \mathrm{~cm}$ Schneider "place hit" Wallstent. These are self-expanding stents loaded on a $9 \mathrm{~F}$ delivery system and when released would continue to expand up to $10 \mathrm{~mm}$ after deployment (Figure 1). Some patients also had dilatation of the stricture with angioplasty probe prior to stent insertion.

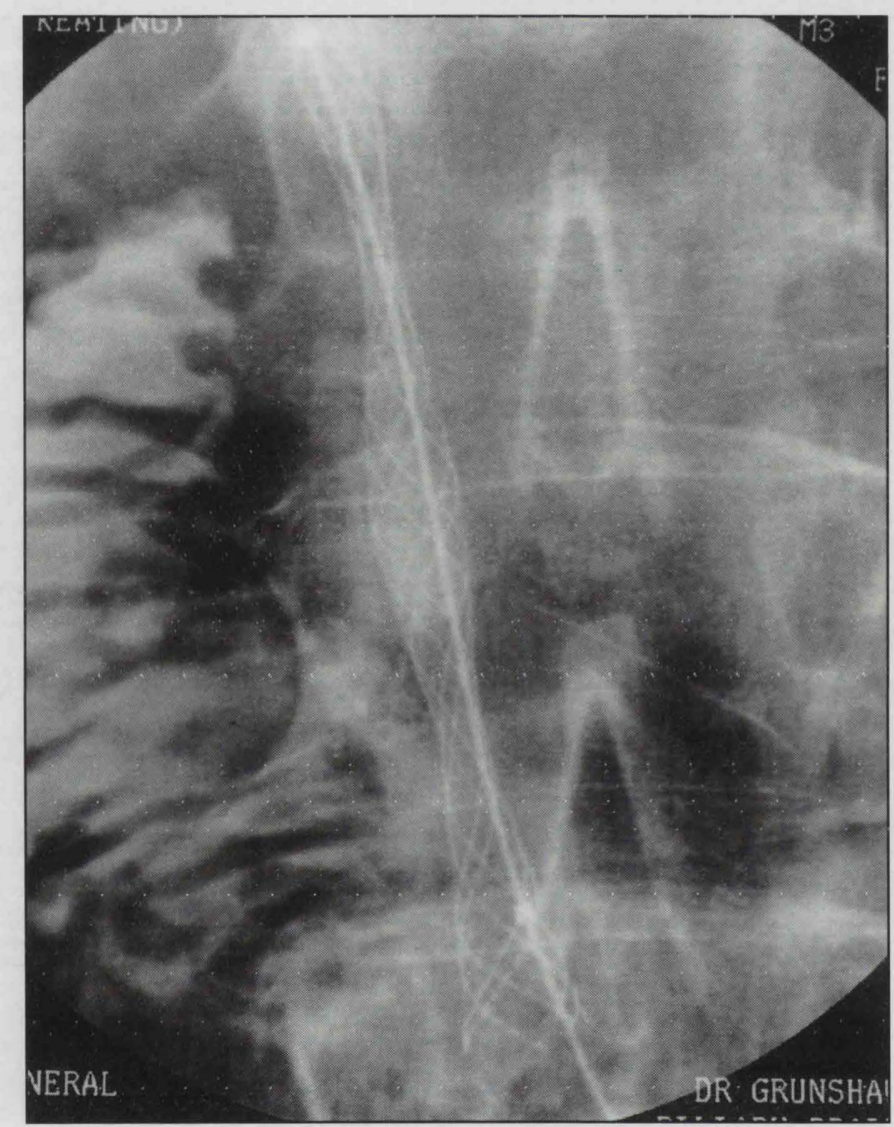

Figure 1 Fully expanded metal stent

\section{RESULTS}

\section{Outcome}

The majority of the patients treated were male and 70 years or older (Figure 2). Sixteen patients $(94 \%)$ had a fall in bilirubin concentration of more than $20 \%$ following the procedure (Figures 3 and 4). One patient with a pancreatic tumour had an insignificant drop in bilirubin of $7 \%$. Only three patients did not leave the hospital and died one to two months later. All three, however, had significant reductions in pruritus and bilirubin level and improvement in appetite. Fourteen patients $(82 \%)$ were discharged following Wallstent insertion and all were able to function independently in the community with palliative care support.

\section{Complications}

Seven patients $(41 \%)$ required re-admission for various reasons following stent insertion. However, only two (12\%) 


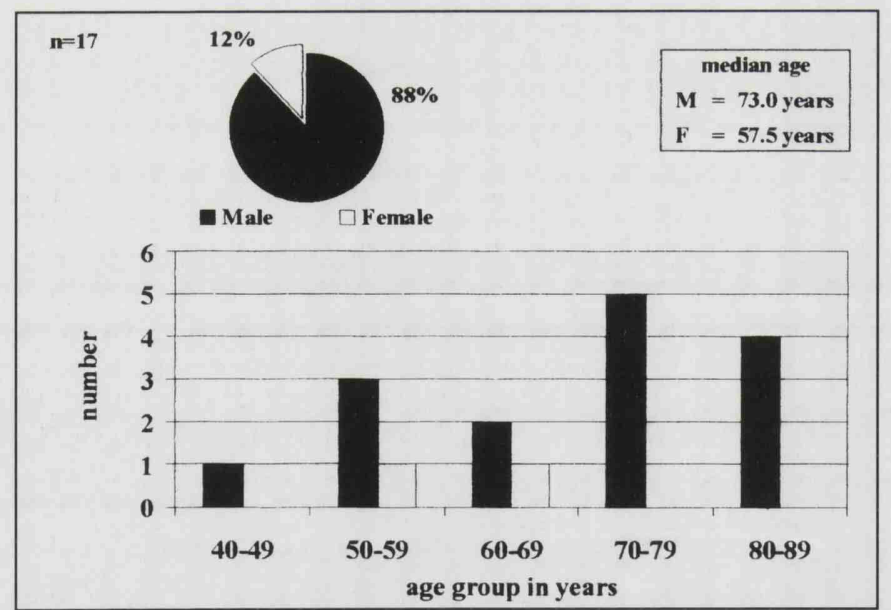

Figure 2 Gender vs age group

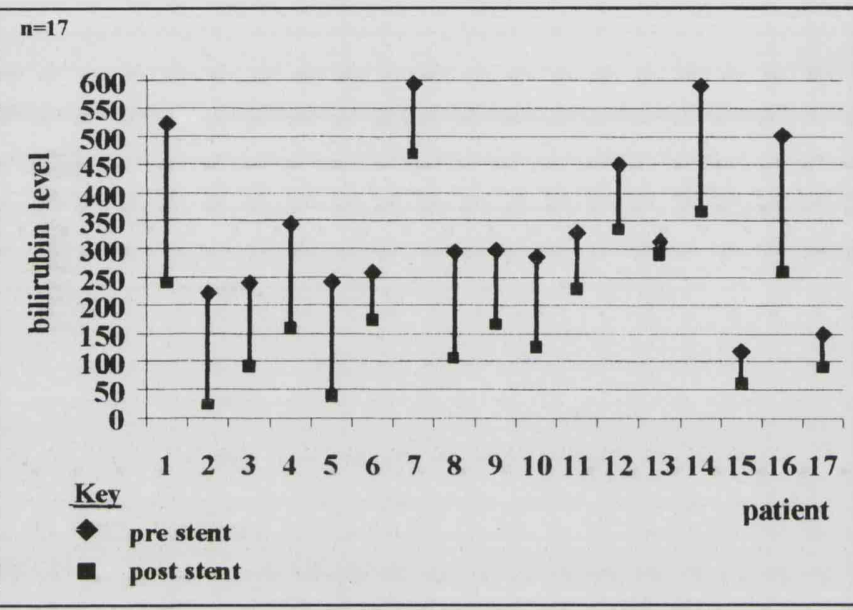

Figure 3 Serum bilirubin pre and post stenting

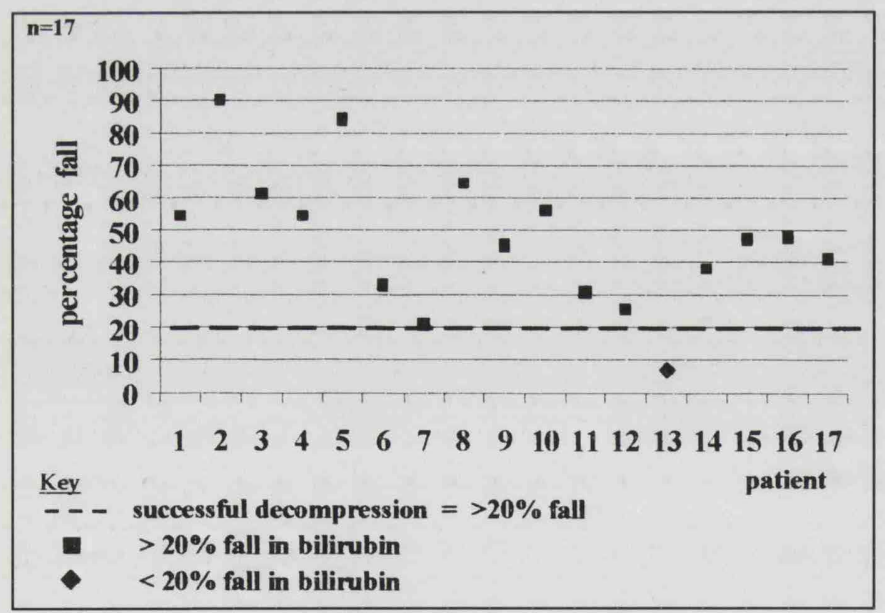

Figure 4 Precentage fall in serum bilirubin

were re-admitted for stent-related problems (re-occlusion and cholangitis). One patient, unfortunately, was re-admitted on eight occasions over three years for recurring cholangitis and re-occlusion despite taking longterm prophylactic antibiotics. These episodes were successfully treated with dredging of the stent and intravenous antibiotics. The five remaining patients were re-admitted for reasons which include gastrointestinal bleeding, ascitic drainage, pulmonary embolism, bone pain, chemotherapy and prostatic biopsy.

\section{Mortality}

There were no procedure-related deaths and the overall thirty-day mortality rate was $6 \%$ (Table 1 ). All the patients died of primary disease. The median survival was longest in patients with cholangiocarcinoma, followed by pancreatic tumour and metastatic disease (42 weeks, 16 weeks and seven weeks respectively) (Figure 5). The overall median survival in our study was 3.5 months (Table 2 ).

\begin{tabular}{|l|c|c|}
\hline Researcher & $\begin{array}{c}\text { 30 day } \\
\text { post stent }\end{array}$ & $\begin{array}{c}\text { Year study } \\
\text { published }\end{array}$ \\
\hline Schima et $a l^{(9)}$ & $39.0 \%$ & 1997 \\
\hline Men et $a l^{(10)}$ & $14.0 \%$ & 1996 \\
\hline Hamy et l $^{(5)}$ & $11.0 \%$ & 1997 \\
\hline Tan et al (UK) & $6.0 \%$ & \\
\hline Lee et $a l^{(11)}$ & $4.0 \%$ & 1997 \\
\hline O'Brien et $a l^{(8)} \quad$ (UK) & $3.5 \%$ & 1995 \\
\hline
\end{tabular}

Table 1 Mortality

\begin{tabular}{|c|c|c|c|}
\hline Study & Country & $\begin{array}{c}\text { Year of } \\
\text { publication }\end{array}$ & $\begin{array}{c}\text { Median } \\
\text { survival } \\
\text { (months) }\end{array}$ \\
\hline O'Brien et $a^{\left({ }^{(8)}\right.}$ & UK & 1995 & 15.1 \\
\hline Lee et $a l^{(11)}$ & Korea & 1997 & 8.8 \\
\hline Schmassmann et al ${ }^{(14)}$ & Switzerland & 1996 & 6.5 \\
\hline Born et al ${ }^{(13)}$ & Germany & 1998 & 6.2 \\
\hline Hamy et $a^{(5)}$ & France & 1997 & 6.0 \\
\hline Vitale et $a^{(12)}$ & USA & 1996 & 4.9 \\
\hline Schima et al ${ }^{(9)}$ & Austria & 1997 & 4.6 \\
\hline Tan et al & UK & & 3.5 \\
\hline
\end{tabular}

Table 2 Survival post-stenting

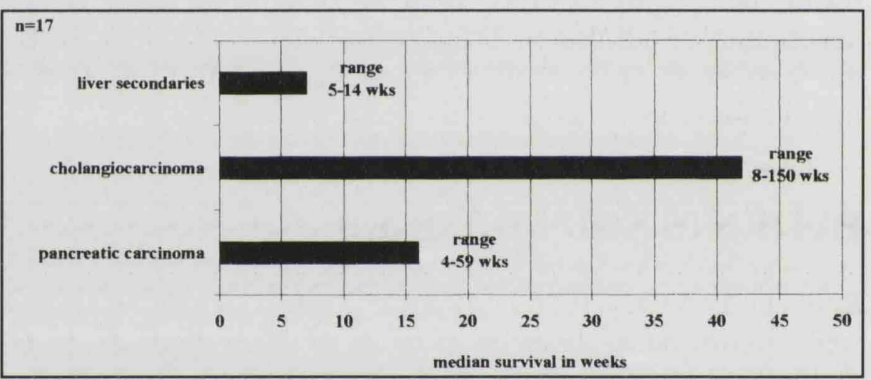

Figure 5 Survival vs diagnosis

\section{DISCUSSION}

Percutaneous self-expanding Wallstents provide good palliation for patients with inoperable malignant obstructive jaundice. Davids et $a l^{(4)}$ found that the median patency was significantly prolonged in patients with metal stents compared with polyethylene stents (273 days versus 176 days). The main reason for metal stent occlusion is tumour in-growth through the meshes, or tumour overgrowth at the end of the stents. Only two patients in our series were readmitted with cholangitis and occlusion $(12 \%)$ and none of these had tumour ingrowth. This may be explained by the shorter survival among our patients due to the advanced stage of their disease.

Up to $40 \%$ of patients in one series had sepsis following stent insertion despite prophylactic antibiotics ${ }^{(5)}$. Our results compared favourably as no patients in our study had early complications following the procedure. The European Wallstent Study Group ${ }^{(6)}$ reported longterm complications manifested by late cholangitis in $18 \%$ of cases and occlusion by biliary sludge in $5 \%$. Our results again compared favourably as only two patients $(12 \%)$ had to be re-admitted for stent occlusion. One patient in our series with cholangiocarcinoma nad to be re-admitted on several 
occasions over a three-year period with recurrent cholangitis and occlusions due to biliary sludge and debris despite taking longterm prophylactic antibiotics. These were treated successfully with balloon trawling of the stent and intravenous antibiotics.

Although high bilirubin level has been described as an unfavourable factor affecting stent patency ${ }^{(7)}$, neither of our two patients re-admitted for occlusion of their metal stent had a particularly high bilirubin level prior to stent insertion (150, 292). Drainage of bile was satisfactory in all our patients following the procedure. The bilirubin level was reduced by more than $20 \%$ in $94 \%$ of cases. This is highly significant as it improves the symptoms of pruritus, increases appetite and hence improves general wellbeing.

Fourteen patients $(82 \%)$ were discharged following a metal stent insertion. All these patients achieved a reasonable level of independent activity of daily living with the support of a palliative care team. Three of our patients (18\%) did not leave the hospital after metal stent insertion as they were too frail. Nonetheless, they all felt better and had improved appetite and reduced pruritus. This is important as it causes less distress for patients and their families. The hospital readmission rate for stent-related problems was considered low $(12 \%)$ with patients spending more time at home.

The overall survival in our series was 3.5 months which is short compared to others (Table 2) and reflects the more advanced disease stage in our patient cohort. Our data compare favourably in terms of thirty-day procedure-related mortality and complications (Table 1). Only one patient in our series died within thirty days post-procedure of primary disease and general deterioration.

In conclusion, our study confirmed that percutaneous Wallstent insertion offers good palliation, improves general wellbeing and enhances the level of independent activity of daily living in patients with malignant biliary obstruction. Percutaneous approach is a good alternative after a failed endoscopic approach in the very frail patients, and this is often preferable to an open operation. This procedure can safely be performed in a district general hospital.

\section{Acknowledgement}

We are indebted to $\mathrm{Dr} N$ Grunshaw for providing the technical support.

\section{REFERENCES}

1 Smith AC, Dowsett JF, Russell RC, Hatfield AR, Cotton PB Randomised trial of endoscopic stenting versus surgical bypass in malignant low bile duct obstruction Lancet 1994 (8938): 1655-60

2 Andersen JR, Sorensen SM, Kruse A, Rokkjaer M, Matsen $P$ Randomised trial of endoprosthesis versus operative bypass in malignant obstructive jaundice Gut 1989;30:1132-35
3 Shepard HA, Royle G, Ross APR, Diba A, Arthur M, Colin-Jones D Endoscopic biliary endoprosthesis in the palliation of malignant obstruction of the distal common bile duct: a randomised trial Br J Surg 1988;75:1166-68

4 Davids PH, Groen AK, Rauws EAJ, Tytgat GNJ, Huibregtse K Randomised trial of self-expanding metal stents versus polyethylene stents for distal malignant biliary obstruction Lancet 1992;340:1488-1492

5 Hamy A, d'Alincourt A, Paineau J, Lerat F, Gibaud H, Lleborgne J, Visset J Percutaneous self-expandable metallic stents and malignant biliary strictures Eur J Surg Oncol 1997;23:403-408

6 Huibregtse K, Carr-Locke DL, Cremer M et al Biliary stent occlusion-a problem solved with self-expanding metal stents? European Wallstent Study Group Endoscopy 1992;24(5): $391-4$

7 Matsuda Y, Shimakura K, Akamatsu T Factors affecting the patency of stents in malignant biliary obstructive disease: univariate and multivariate analysis Am J Gastroenterol 1991;86:843-49

8 O'Brien S, Hatfield ARW, Craig PI, Williams SP A threeyear follow-up of self-expanding metal stents in the endoscopic palliation of longterm survivals with malignant biliary obstruction Gut 1995;36:618-621

9 Schima W, Prokesch R, Osterreicher C, Thurnher S, Fugger R, Schofl R, Havelec L, Lammer J Biliary Wallstent endoprostheses in malignant biliary obstruction: long term results with regard to the type of obstruction. Clin Radiol $1997 ; 52(3): 213-9$

10 Men S, Hekimoglu B, Kaderoglu H, Pinar A, Conkbayir I, Soylu SO, Bulut A, Yandakci K, Baran I, Aran Y Palliation of malignant obstructive jaundice. Use of self-expandable metal stents Acta Radiol 1996;37 (3 Pt 1):259-66

11 Lee BH, Choe DH, Lee JH, Kim KH, Chin SY Metallic stents in malignant biliary obstruction; prospective long-term clinical results Am J Roentgenol 1997;168(3):741-5

12 Vitale GC, Larson GM, George M, Tatum C Management of malignant biliary stricture with self-expanding metallic stent Surg Endoscopy 1996;10(10):970-3

13 Born P, Rosch T, Bruhl K, Sandschin W, Frimberger E, Allescher H, Classen M Long-term results of endoscopic treatment of biliary duct obstruction due to pancreatic disease Hepatogastroenterology 1998;45(21):833-9

14 Schmassman A, von Gunten E, Knuchel J, Scheurer U, Fehr HF, Halter F Wallstents versus plastic stents in malignant biliary obstruction: effects of stent patency of the first and second stents on patient compliance and survival Am J Gastroenterol 1996;91(4):654-9 